\title{
Acute physiological changes caused by complement activators and amphotericin B-containing liposomes in mice
}

This article was published in the following Dove Medical Press journal: International Journal of Nanomedicine

\author{
Erik Örfi, ${ }^{1,2}$ Tamás \\ Mészáros, ${ }^{1,2}$ Mark \\ Hennies, ${ }^{3}$ Tamás Fülöp, ${ }^{1,2}$ \\ László Dézsi, ${ }^{1,2}$ Alexander \\ Nardocci,' László \\ Rosivall, ${ }^{1,2}$ Péter Hamar, ${ }^{4,5}$ \\ Barry W Neun, ${ }^{6}$ Marina \\ A Dobrovolskaia, ${ }^{6}$ János \\ Szebeni, ${ }^{1,2,7, *}$ Gábor \\ Szénási ${ }^{1,8, *}$
}

'Nanomedicine Research and Education Center, Institute of Pathophysiology, Semmelweis University, Budapest, Hungary; ${ }^{2}$ SeroScience LCC., Cambridge, MA, USA; ${ }^{3}$ TECOdevelopment $\mathrm{GmbH}$, Rheinbach, Germany; ${ }^{4}$ Institute of Clinical Experimental Research, Semmelweis University, Budapest, Hungary; ${ }^{5}$ Institute for Translational Medicine, Medical School, University of Pécs, Pécs, Hungary; ${ }^{6}$ Nanotechnology Characterization Laboratory, Frederick National Laboratory for Cancer Research, National Cancer Institute, Frederick, MD, USA; ${ }^{7}$ Department of Nanobiotechnology and Regenerative Medicine, Faculty of Health, Miskolc University, Miskolc, Hungary; ${ }^{8}$ Institute of Pathophysiology, Semmelweis University, Budapest, Hungary

*These authors contributed equally to this work

Correspondence: János Szebeni

Nanomedicine Research and Education

Center, Institute of Pathophysiology,

Semmelweis University, 1089 Nagyvárad

tér 4, Budapest, Hungary

Tel +36 304150007

Fax +36 I 2100100

Email jszebeni2@gmail.com
Purpose: Undesirable complement (C) activation by nanomedicines can entail an adverse immune reaction known as $\mathrm{C}$ activation-related pseudoallergy (CARPA) in sensitive patients. The syndrome includes cardiopulmonary, hemodynamic, and a variety of other physiological changes that have been well described in man, pigs, dogs, and rats. However, the information on CARPA is scarce and ambiguous in mice, a species widely used in preclinical studies. The present study aimed to fill this gap by exploring signs of CARPA in mice following i.v. administration of AmBisome and Abelcet, which are nano-formulations of Amphotericin B with high risk to cause CARPA.

Materials and methods: Anesthetized NMRI mice were intravenously injected with liposomal amphotericin B (Abelcet and AmBisome; 30-300 mg phospholipid/kg), drug-free high cholesterol multilamellar vesicles (HC-MLV), and positive controls, cobra venom factor (CVF) and zymosan, followed by the measurement of blood pressure (BP), heart rate, white blood cell, and platelet counts and plasma thromboxane B2 (TXB2) levels. C activation was assessed by C3a ELISA, a C3 consumption assay (PAN-C3) and a modified sheep red blood cell hemolytic assay. Results: All test agents, except HC-MLV, caused transient hypertension, thrombocytopenia, and elevation of plasma TXB2, which were paralleled by significant rises of plasma C3a in CVF and zymosan-treated animals, wherein the initial hypertension turned into hypotension and shock. Abelcet and AmBisome caused minor, delayed rise of $\mathrm{C} 3 \mathrm{a}$ that was not associated with hypertension. The C3a receptor inhibitor SB-290157 attenuated the hypertension caused by Abelcet and decreased the BP thereafter.

Conclusion: The parallelism between $\mathrm{C} 3$ a anaphylatoxin production and severity of physiological changes caused by the different agents is consistent with CARPA underlying these changes. Although the reactive dose of liposomal phospholipids was substantially higher than that in other species (pigs, dogs), the mouse seems suitable for studying the mechanism of hypersensitivity reactions to liposomal formulations of amphotericin $\mathrm{B}$, a frequent side effect of these drugs.

Keywords: hypersensitivity, infusion reactions, zymosan, cobra venom factor, TXB2, cholesterol, anaphylatoxins, platelets

\section{Introduction}

Complement (C) activation-related pseudoallergy (CARPA) can be a serious side effect of liposomal drugs, biologicals, and many other modern therapeutic and diagnostic agents. ${ }^{1,2}$ The leading symptoms of CARPA are mild-to-severe circulatory changes that include hemodynamic (blood pressure, BP) changes, flushing, rash, urticaria, chest and back pain, dyspnea, fever, coughing, and many other common symptoms of acute allergy. ${ }^{1,2}$ Regarding the mechanisms of hemodynamic changes, stimulation of anaphylatoxin (AT) receptors CR3a and CR5a are known to alter BP. ${ }^{3-5}$ It has also 
been clearly demonstrated in several rodent species that activation of CR5a decreases BP, and the inhibition of CR5a can avoid hypotension caused by $\mathrm{C}$ activation. ${ }^{3}$ On the contrary, stimulation of CR3a can induce hypertension. ${ }^{3}$ However, the relative contribution of different $\mathrm{C}$ receptor activations and other bioactive substances to cardiopulmonary distress has not yet been dissected.

This study focused on the effects of AmBisome and Abelcet in mice, two clinically available liposomal formulations of amphotericin B, which are known to cause CARPA in man in a relatively high percentage $(>10 \%),{ }^{6-10}$ and which were found in preliminary experiments to be effective triggers of hemodynamic changes in mice. These changes have previously been studied in man, ${ }^{11,12}$ pigs, ${ }^{13-18}$ minipigs,${ }^{19}$ and rats, ${ }^{20}$ but, surprisingly, not in mice, despite the common use of this species in immunology, genetic, physiology, and toxicology studies. As a positive control we used known activators of the $\mathrm{C}$ system; zymosan and cobra venom factor (CVF). Since the structures of AmBisome and Abelcet are substantially different (they consist of small unilamellar liposomes and large multimicron ribbon-like lipid complexes, respectively), ${ }^{21,22}$ our experiments also addressed the question of whether the size of liposomes has an impact on the hemodynamic and other changes. In addition, we tested large multilamellar liposomes with high (71\%) cholesterol content (HC-MLV), as these liposomes induced strong hemodynamic derangements in rats ${ }^{23}$ and pigs. ${ }^{18}$

\section{Materials and methods Chemicals, liposomes, and ELISA kits}

Zymosan and the $\alpha$-sheep RBC antibody (hemolysin) were purchased from Sigma (St Louis, MO, USA). AmBisome and Abelcet were obtained from Semmelweis University Pharmacy (Budapest, Hungary). HC-MLVs were prepared as described previously. ${ }^{23}$ The mouse C3a and PAN C3 ELISA kits, and CVF were obtained from TECOMedical (Sissach, Switzerland). The TXB2 ELISA was from Cayman Chemical (Ann Arbor, MI, USA). Vacutainers with hirudin were purchased from Roche (Budapest, Hungary).

\section{Animals}

We used an outbred mouse strain originally developed at the Naval Medical Research Institute (Crl: NMRI BR) and C57B16/N mice for the bridging study. SPF male mice weighing 27-35 g were purchased from Toxicoop Ltd (Budapest, Hungary). Mice had free access to standard rodent chow (Altromin standard diet, Germany) and tap water. The experiments were started after a minimum of 1-week adaptation following arrival.

\section{Ethical approval}

All procedures were performed in accordance with guidelines set by the National Institutes of Health (USA) and the Hungarian law on animal care and protection. The protocol was approved by the Institutional Ethical Committee for Animal Care and Use of Semmelweis University (registration number: PEI-001/3948-6/2014).

\section{Experimental protocol}

Mice were anesthetized with pentobarbital (60 mg/kg i.p.), and the right carotid artery and the left jugular vein were cannulated with PP10 tubing for measuring BP and for drug administration, respectively. The BP was measured using a BPR-02 pressure transducer (Experimetria Ltd., Budapest, Hungary), an HG-01D BP amplifier (Experimetria Ltd.) and a PowerLab data acquisition system (ADInstruments Ltd., Oxford, UK). Mean BP (MBP) and heart rate (HR) were derived from the pulsatile BP curve, monitored and recorded in a desktop computer using LabChart data analysis software (ADInstruments Ltd.). These recordings were continuous during the experiment, which started with 10 minutes baseline recording, followed by i.v. injection of test materials (within 1 minute) in a volume of $10 \mathrm{~mL} / \mathrm{kg}$. Separate groups of animals were anesthetized with isoflurane $(2 \%-3 \%)$ inhalation, and the test substances were injected via the tail vein. The animals were then treated with lepirudin (Refludan, Aventis Pharma, $0.15 \mathrm{mg} / \mathrm{g}$ i.p.) to prevent blood coagulation. Mollnes et $\mathrm{al}^{25}$ and Cedrone et $\mathrm{al}^{24}$ have described that a similar dose of hirudin does not interfere with $\mathrm{C}$ activation, which was confirmed in our experiments as well. The animals were sacrificed by cervical dislocation, and then blood was collected from the chest cavity after cutting the caval vein. The protocol of the study is illustrated in Figure 1.

\section{Measuring plasma extravasation}

The mice were anesthetized with isoflurane, and zymosan $(30 \mathrm{mg} / \mathrm{kg})$ was injected via the tail vein, and then Evans blue $(100 \mathrm{mg} / \mathrm{mL})$ was administered via the retroorbital sinus. 10 minutes later the animals were killed by cervical dislocation, and, after opening the chest and cutting the vena cava, they were perfused with $10 \mathrm{~mL}$ and $0.5 \mathrm{~mL}$ cold saline via the left and right ventricles, respectively. Samples dissected from various organs were weighed and then transferred to $0.5 \mathrm{~mL}$ formamide. Evans blue was extracted from the tissues for 24 hours at room temperature, and the dye concentration was measured at $620 \mathrm{nM}$ in a plate reader.

\section{Complement assays}

Mouse C3a was measured by TECOMedical's mouse C3a ELISA kit. C3 consumption was measured by Quidel's PAN 


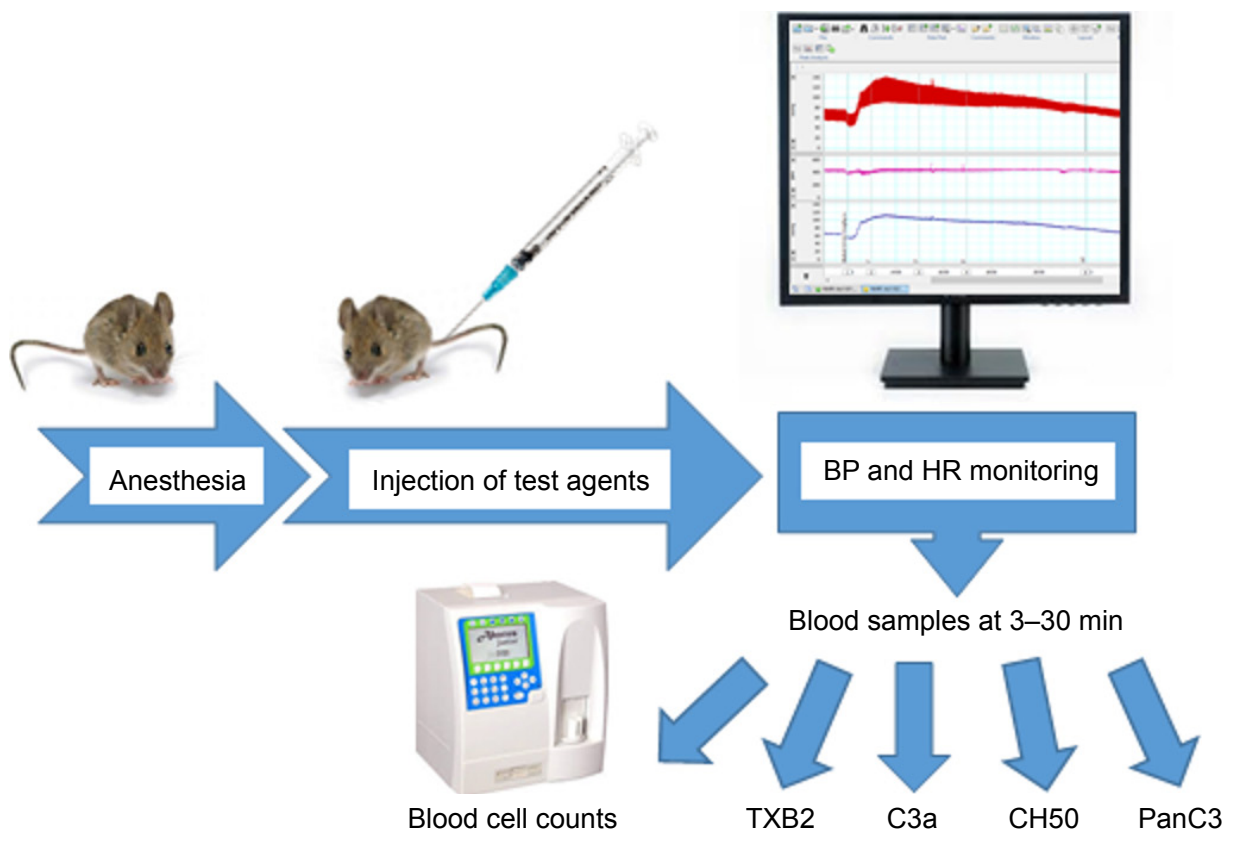

Figure I Schematic outline of the study design.

Abbreviations: BP, blood pressure; HR, heart rate.

C3-kit, and total C consumption was measured by a modified sheep red cell hemolytic assay (SRBC), as described previously. ${ }^{20}$

\section{Handling of blood samples for the different analyses}

Blood was collected into three types of tubes as follows; for the PAN-C3 and SRBC assays the tubes contained $15 \mu \mathrm{g}$ Lepirudin (in $10 \mu \mathrm{L}$ ); for $\mathrm{C} 3 \mathrm{a}$ and blood cell counting the tubes contained K3EDTA (MiniCollect ${ }^{\circledR}$, Greiner Bio-One Hungary Kft, Budapest, Hungary) and for the TXB2 assay we used tubes that contained K3EDTA and indomethacin (10 $\mu \mathrm{g} /$ tube, $5 \mu \mathrm{L})$.

\section{Statistical analysis}

All data presented are mean \pm SEM. All treated groups were compared to the saline control group using one-way ANOVA followed by Dunnett's multiple comparisons test, but the treated groups were not compared to each other. If either Brown-Forsythe test or Bartlett's test indicated significant inhomogeneity of the data among the groups, the data were $\log$ transformed for statistical analysis. The hemodynamic effects were analyzed with one-way ANOVA for repeated measurements followed by Dunnett's multiple comparisons test. The effects of SB290157 were evaluated using two-way ANOVA for repeated measurements. The tests were performed using GraphPad Prism version six for Windows (GraphPad Software, La Jolla, CA, USA).

\section{Results}

\section{Basic characteristics of liposomes}

Table 1 presents some basic information on the liposomes used in this study. The liposomes were selected by their known CARPA-genic activity in humans or in different animal models.

\section{Hemodynamic effects of $C$ activators and liposomes}

Preliminary mouse studies were conducted to select the doses, which effectively cause significant, quantitative and analyzable

Table I Basic characteristics of liposomes

\begin{tabular}{|c|c|c|c|c|c|}
\hline Name & API & Lipids & Shape and nominal size & Origin & References \\
\hline AmBisome & Amphotericin B & HSPC, Chol, DSPG, $\alpha T$ & Spherical SUV, $<100 \mathrm{~nm}$ & Gilead, USA & 1,2 \\
\hline Abelcet & Amphotericin B & DMPC, DMPG & $\begin{array}{l}\text { Ribbon-like } \\
\text { complexes }>10 \mu \mathrm{m}\end{array}$ & $\begin{array}{l}\text { Leadiant Biosciences, } \\
\text { Inc., MD, USA }\end{array}$ & 3,4 \\
\hline HC-MLV & PBS & HSPC, Chol, DSPG & $0.8-10 \mu \mathrm{m}$ MLV & Self-made & 5 \\
\hline
\end{tabular}

Abbreviations: $\alpha \mathrm{T}, \alpha$-totocopherol; API, active pharmaceutical ingredient; Chol, cholesterol; DSPG, distearoyl-phosphatidylglycerol; HC, high cholesterol; HSPC, hydrogenated soy phosphatidylcholine; MLV, multilamellar vesicles; SUV, small unilamellar vesicles; DMPC, I- $\alpha$-dimyristoylphosphatidylcholin; DMPG, I- $\alpha$-dimyristoylphosphatidylglycerol. 
changes in MBP (data not shown). In the case of liposomal formulations, the doses were 30-300 mg phospholipid $/ \mathrm{kg}$, which are nearly 2-orders of magnitude higher than that required to trigger CARPA in pigs $(\sim 0.5 \mathrm{mg} / \mathrm{kg})$. The MBP

\section{A}
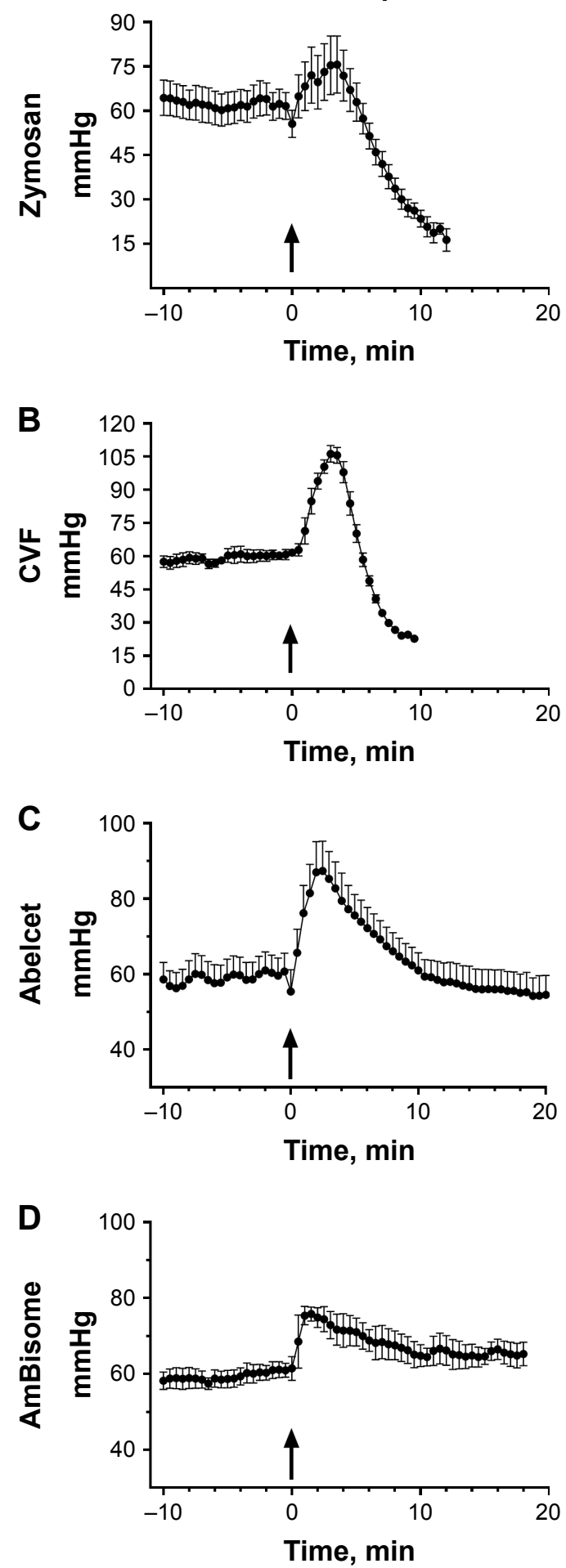

and HR changes in response to the positive controls and liposomal formulations are shown in Figure 2. The positive controls, zymosan (Figure 2A) and CVF (Figure 2B), and the liposomal amphotericin B formulations, Abelcet (Figure 2C)
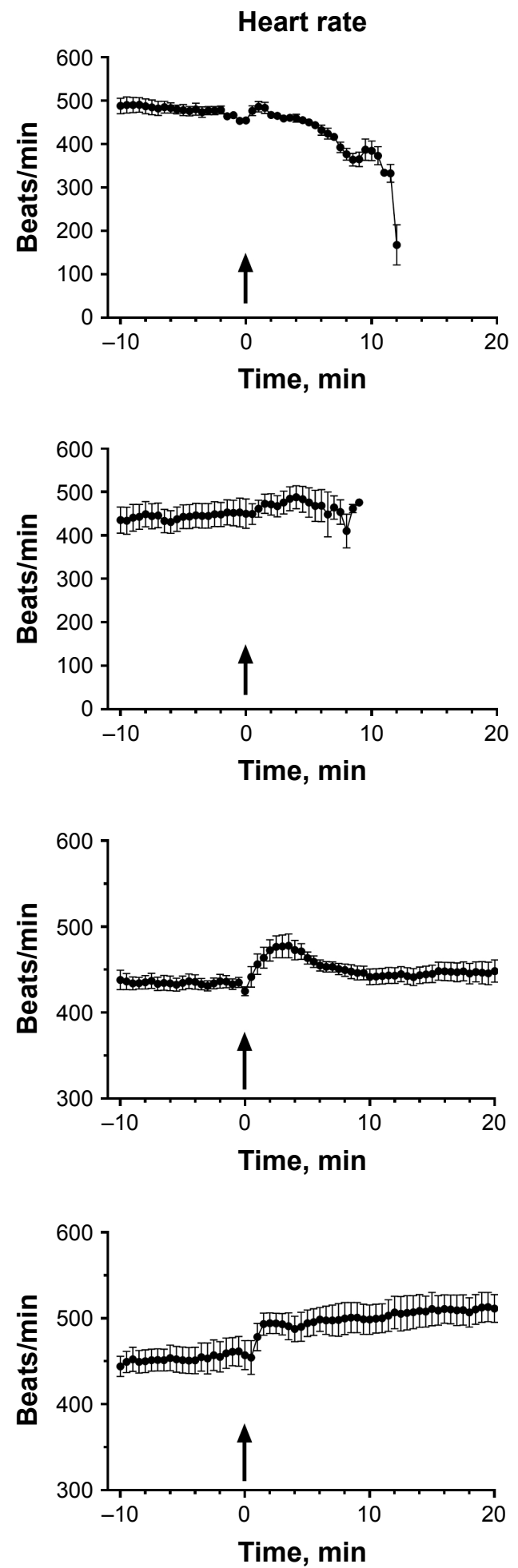

Figure 2 Hemodynamic changes caused by complement activators and liposomes in male NMRI mice $(n=5-6)$.

Note: (A) Zymosan (30 mg/kg), (B) CVF $100 \mathrm{U} / \mathrm{kg})$, (C) Abelcet (30 mg/kg), and (D) AmBisome (300 mg/kg) were administered as i.v. bolus at times indicated by the arrows. Abbreviations: CVF, cobra venom factor; NMRI, Naval Medical Research Institute. 
and AmBisome (Figure 2D) triggered essentially similar transient hypertension. In the animals treated with these samples the rise of MBP started at $\approx 1$ minute, peaked at 2-4 minutes and gradually declined within 10-15 minutes after treatment. However, there was a remarkable difference in the hemodynamic effects between $\mathrm{C}$ activators (Figure $2 \mathrm{~A}$ and $\mathrm{B}$ ) and liposomes (Figure 2C and D). While the MBP curve returned to normal after the hypertensive phase if liposomal amphotericin B formulations were administered, it progressed into hypotensive shock after treatment with positive controls. The HC-MLV at $300 \mathrm{mg} / \mathrm{kg}$ i.v. caused a minor, insignificant effect on the MBP (data not shown). The HR changes were inconsistent between the samples and varied from a gradual decline in the case of zymosan to a gradual rise in the case of AmBisome.

Taken together, these data confirm that both the known $\mathrm{C}$ activators (zymosan and CVF) and the liposomal amphotericin B formulations (Ambisome and Abelcet) can cause MBP changes in mice that are characteristic of CARPA observed in other species.

\section{Hematological and innate immune responses to $\mathrm{C}$ activators and liposomes}

In addition to the hemodynamic changes, the typical CARPA responses in pigs and rats include changes of blood cell counts and plasma markers of nonspecific humoral and cellular immune stimulation (C activation markers, TXA2). ${ }^{18,20}$ Thus, we explored these changes in mice treated with $\mathrm{C}$ activators and liposomes. The changes of TXA2 were assessed by measuring its stable metabolite, TXB2. ${ }^{26}$

As shown in Figure 3, the same dose of zymosan that caused a rise in MBP (Figure 2) led to significant thrombocytopenia (Figure 3A), leukocytosis (Figure 3B), erythrocytosis (Figure 3C), TXB2 release (Figure 3D), and C consumption (Figure 3E) within 2-3 minutes of treatment, providing evidence of CARPA. The gradual, up to $\approx 70 \%$, rise of RBC (Figure 3C) was most likely due to hemoconcentration, which is known to be a consequence of AT-induced capillary leakage, ie, indirect proof of $\mathrm{C}$ activation. In fact, zymosan caused plasma extravasation in the lung, gastrocnemius muscle, skin, and small intestine at 10 minutes after its administration (Figure 3F).
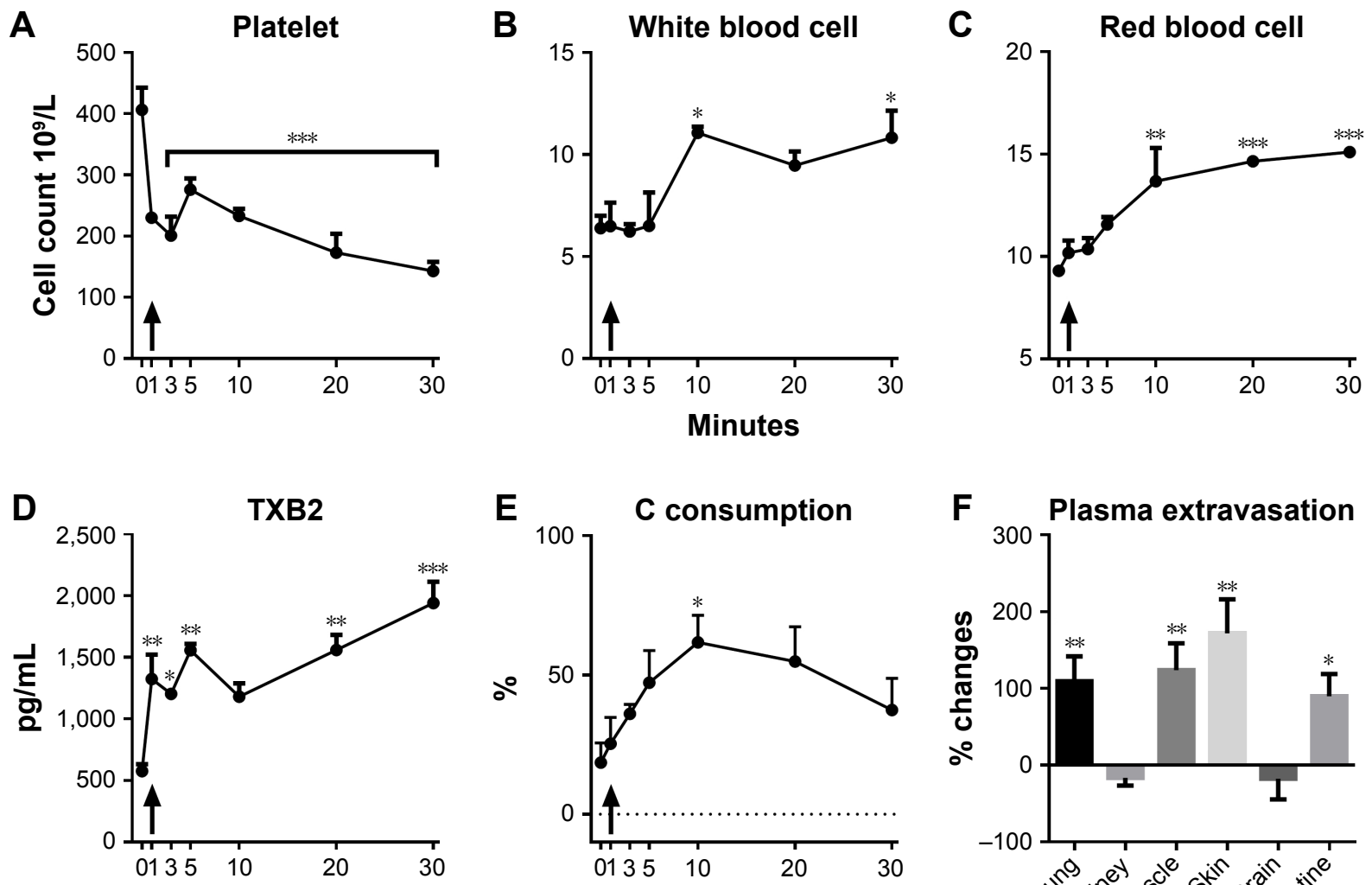

E
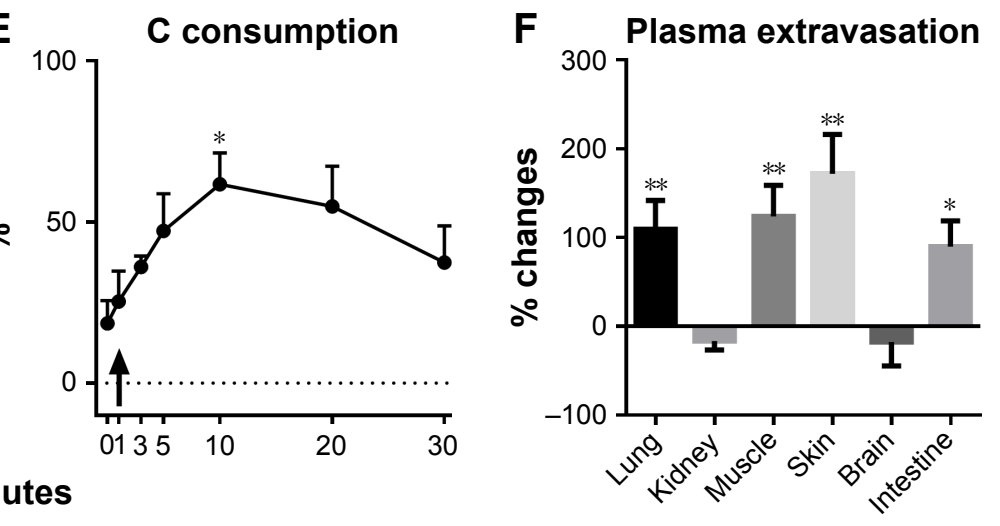

Figure 3 Hematological changes (A-C), TXB2 levels (D), complement consumption (E), and plasma extravasation of Evans blue in various organs (F) of Zymosan-treated (30 mg/kg i.v.) male NMRI mice.

Notes: The arrow indicates the time of treatment. The number of mice is $n=3-5$ for each time. Complement consumption was assessed using a modified sheep red blood cell hemolytic assay. The number of animals is eleven for the plasma extravasation test. Significant differences $(* P<0.05 ; * * P<0.01$; $* * * P<0.001)$ are shown in comparison to the baseline or vehicle treated control group in the case of extravasation.

Abbreviations: NMRI, Naval Medical Research Institute; TXB2, thromboxane B2 levels. 

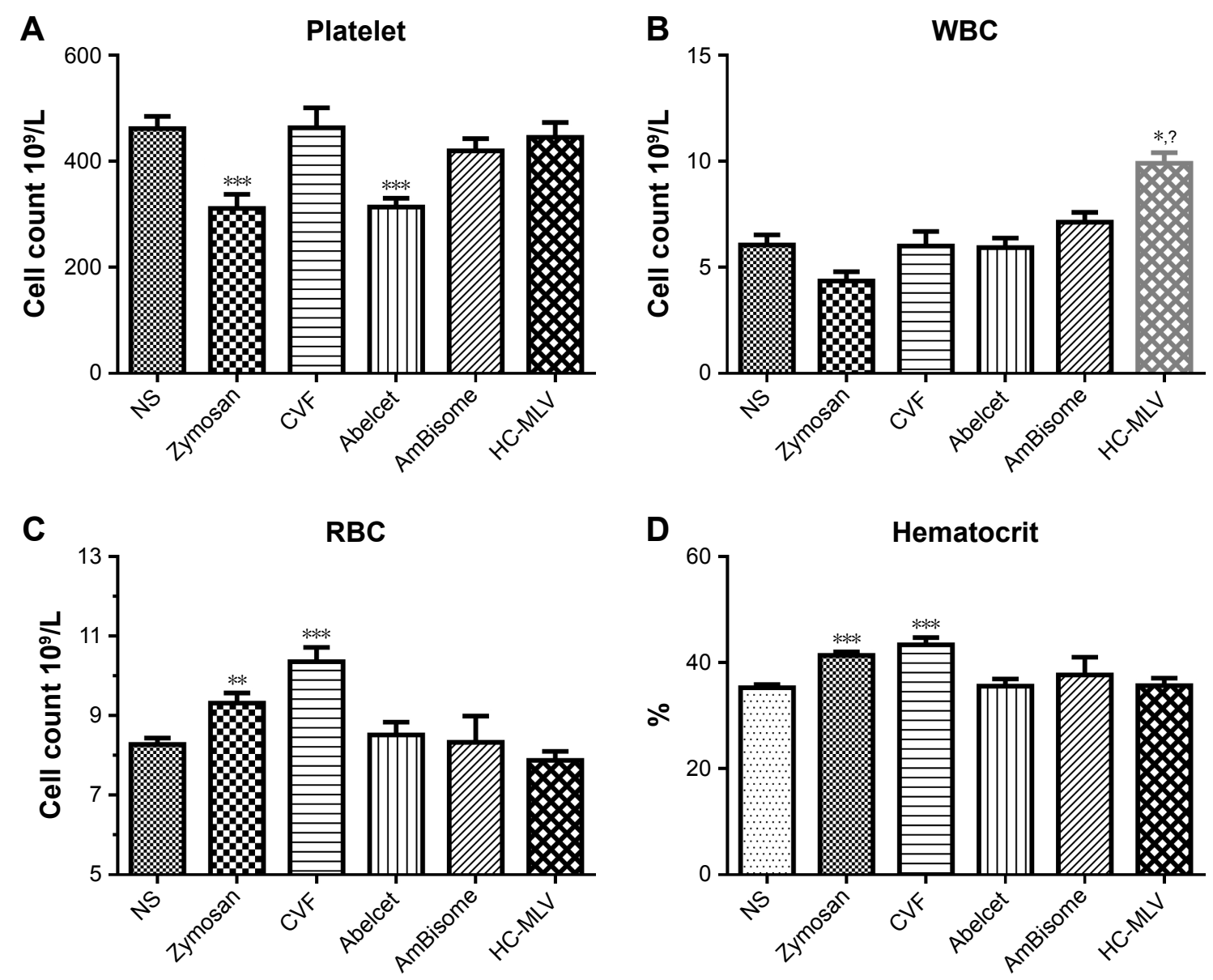

Figure 4 Hematological effects of $C$ activators and liposomes.

Notes: A-D show the maximal changes of platelets, WBC, RBC and hematocrit, respectively, following injection of the $C$ activators and liposomes, specified on the $x$-axis. $\mathrm{n}=8-1 \mathrm{I}$ mice for each assay. Significant differences $\left({ }^{* * P}<0.0 \mathrm{I} ;{ }^{* * * P}<0.00 \mathrm{I}\right)$ relative to the group treated with saline (NS). ${ }^{*} \mathrm{HC}-\mathrm{MLV}$ interfered with the detection of WBC, these data are not reliable.

Abbreviations: CVF, cobra venom factor; HC-MLV, high cholesterol multilamellar vesicles; RBC, red blood cell; WBC, white blood cell.

Figure 4 shows the blood cell changes caused by other test agents in this study at 3-5 minutes after treatments. Despite uniform hypertension caused by both $\mathrm{C}$ activators and liposomal amphotericin $\mathrm{B}$ formulations (Figure 2), thrombocytopenia (Figure 4A) was seen only after zymosan and Abelcet treatment, and erythrocytosis (Figure 4C) and hematocrit (HTC) rises (Figure 4D) were seen only after zymosan and CVF. HCMLV interfered with the detection of white blood cell (WBC) (Figure 4B), as a consequence of its multi-micron size. ${ }^{23}$

Figure 5 shows the effects of various treatments on $\mathrm{C}$ activation markers 3-5 minutes after injection. As expected, zymosan and $\mathrm{CVF}$ caused massive changes in all three tests (C consumption, PAN-C3 and $\mathrm{C} 3 \mathrm{a}$ in Figure 5A-C, respectively), indicating strong $\mathrm{C}$ activation. Interestingly, the relative changes caused by zymosan and CVF differed in these assays, suggesting differential sensitivity to these agents. In contrast, none of the liposomes caused significant changes in any of these assays (Figure 5A-C). Based on the dynamic window, data scattering and (lack of) negative values (which reflect matrix effects near baseline), the C3a ELISA (Figure 5C) proved to be the most consistent quantitative assay for $\mathrm{C}$ activation in mice under the conditions of this study.

Figure 5D shows that plasma TXB2 was significantly increased by the $\mathrm{C}$ activators and liposomes at 3-5 minutes (except HC-MLV), which increases run in parallel with the hypertensive effects of these agents (Figure 2). Thus, the early release of TXB2 may explain the hypertensive effect of liposomes, which could not be associated with $\mathrm{C} 3$ a production.

The lack of AT production by AmBisome and Abelcet in mouse blood at 3-5 minutes post-treatment contradicts the findings on strong $\mathrm{C}$ activation by these drugs in human serum, leading us to further explore this phenomenon. In additional experiments we measured, therefore, the rise of C3a over longer than 3-5 minutes, and, in fact, at 10, 20, and 30 minutes after treatment we obtained evidence of significant $\mathrm{C}$ activation by AmBisome and Abelcet (Figure 5E) as well. 

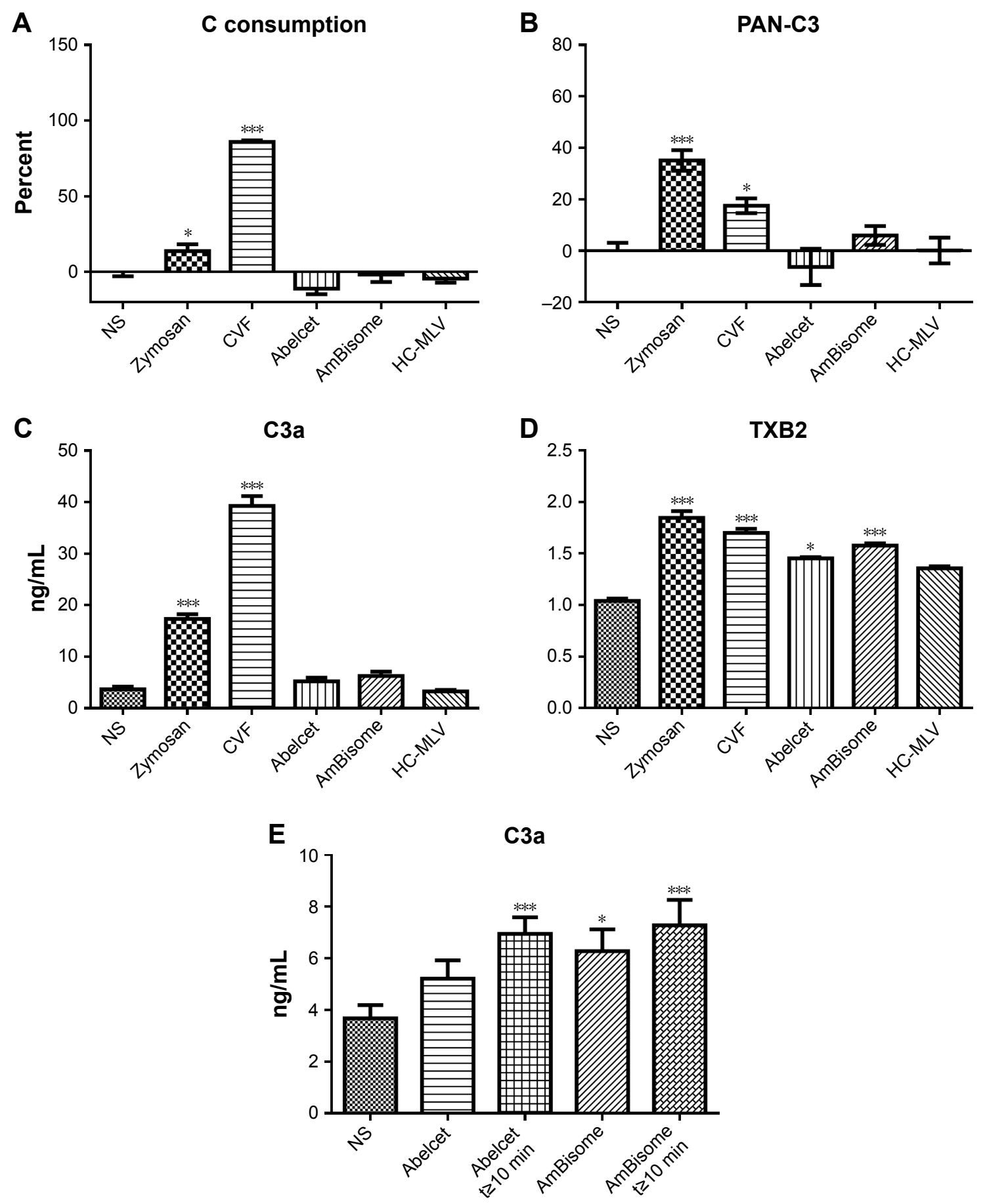

Figure 5 Effects of $C$ activators and liposomes on biomarkers of complement activation and TXB2 levels. (A) Hemolytic $C$ consumed, measured in a modified sheep red blood cell hemolytic assay, (B) C3 consumption evaluated by the PAN-C3 assay, and (C) mouse C3a, measured by mouse specific ELISA. (D) TXB2 levels measured by ELISA. $\mathrm{n}=8-1$ I mice for each assay. (E) The effects of Abelecet and AmBisome on plasma C3a measured at 3 minutes as well as 10, 20, and 30 minutes after treatment (the results for 10-30 minutes are combined as $\mathrm{C} 3$ a levels were similar at 10,20, and 30 minutes).

Notes: $\mathrm{n}=3-5$ mice at each time. Significant differences $(* P<0.05 ; * * * P<0.001)$ relative to the group treated with saline (NS).

Abbreviations: CVF, cobra venom factor; HC-MLV, high cholesterol multilamellar vesicles; RBC, red blood cell; TXB2, thromboxane B2 levels; WBC, white blood cell.

These observations suggest that liposomes can activate mouse $\mathrm{C}$ in vivo; however, this activation is weak, so that net rise of AT becomes manifest slower than the release of TXA2 and development of systemic hypertension.

\section{Effect of a C3aR antagonist on Abelcet- induced hypertension}

Previous studies in pigs indicated a causal role of $\mathrm{C}$ activation in the hemodynamic changes caused by liposomes, while the 

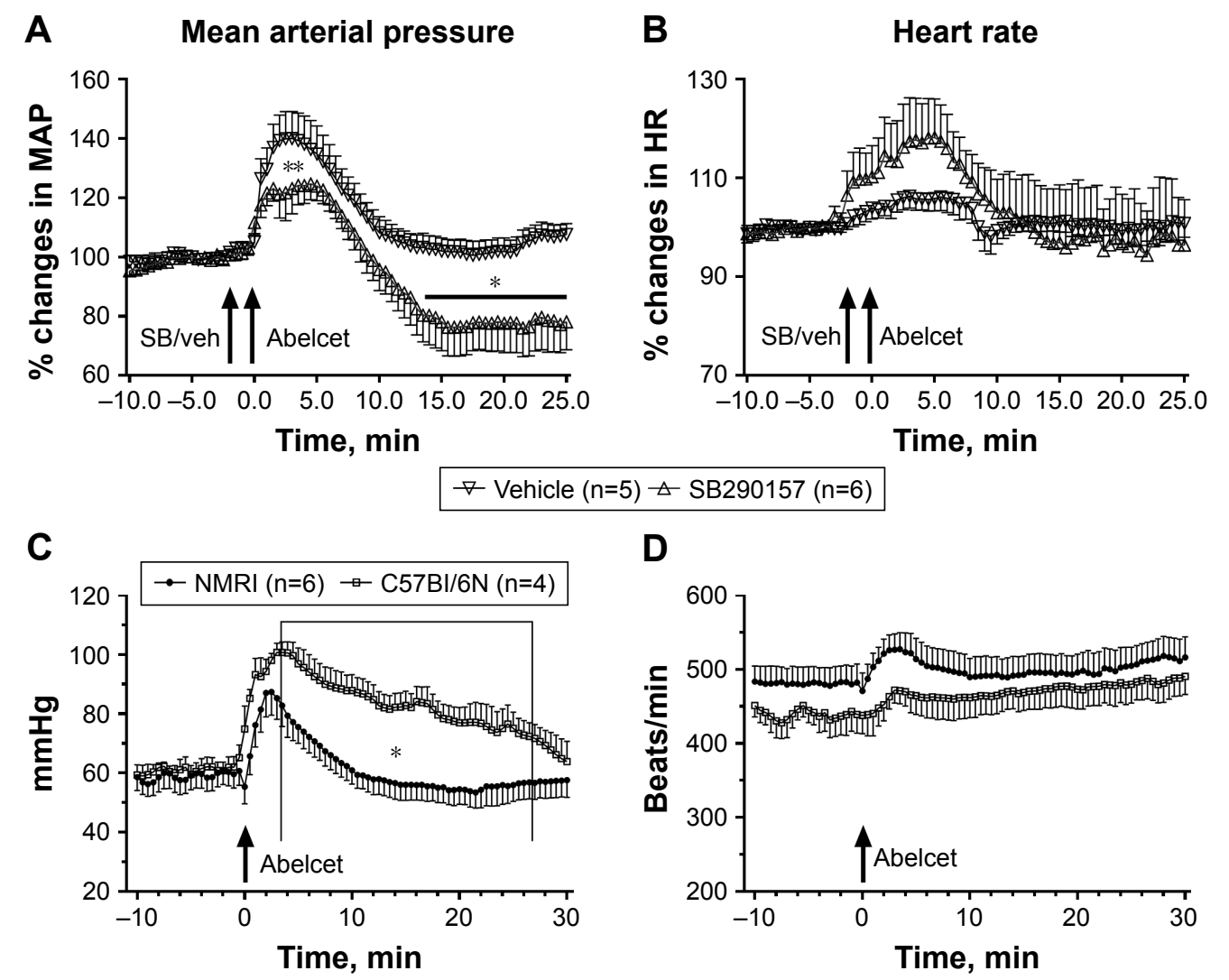

$\triangle=5) \triangle \operatorname{SB} 290157(n=6)$

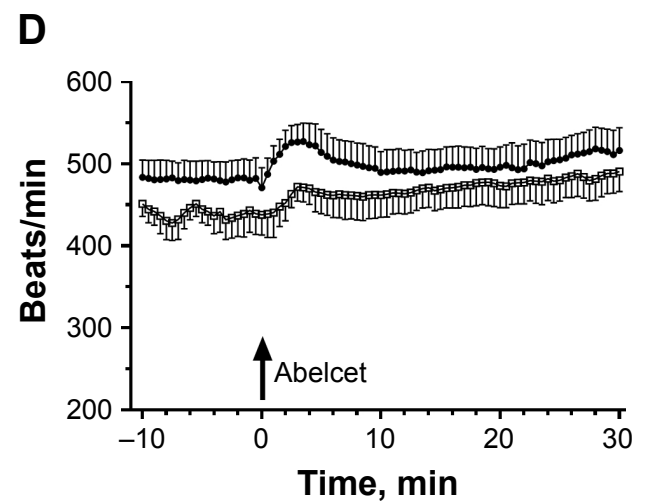

Figure 6 Effects of SB-290I57 on the blood pressure and HR changes caused by Abelcet and comparison of the effects of Abelcet in NMRI and C57BI/6N mice. Changes in mean arterial pressure (A) and HR (B) after pretreatment with SB-290I57 at $10 \mathrm{mg} / \mathrm{kg}$ i.v. or its vehicle ( $5 \%$ DMSO in saline) and then administration of Abelcet at $30 \mathrm{mg} / \mathrm{kg}$ i.v. Comparison of changes in mean arterial pressure (C) and HR (D) in NMRI and C57BI/6N mice after administration of Abelcet at $30 \mathrm{mg} / \mathrm{kg}$ i.v.

Note: $* P<0.05 ; * * P<0.01$; significant differences between the two groups.

Abbreviations: HR, heart rate; MAP, mean arterial pressure; NMRI, Naval Medical Research Institute.

absence of C3a production by liposomes raises the possibility of $\mathrm{C}$-independent hemodynamic derangement in mice, ie, C-independent pseudoallergy (CIPA). To explore the latter possibility further, we tested the effect of SB-290157, a C3aR antagonist, on Abelcet-induced hypertension. It was assumed that if this compound inhibits the rise of MBP in mice that would serve direct evidence of the causal involvement of $\mathrm{C}$ activation in hypertension. As shown in Figure 6A, in fact, SB-290157 significantly attenuated the hypertensive effect of Abelcet; however, this effect was not complete and SB-290157 also caused significant tachycardia (Figure 6B), which is a CARPA symptom. Thus, although the effect of SB-290157 is consistent with a role of $\mathrm{C}$ activation in the liposome-induced hemodynamic changes, it did not provide conclusive evidence regarding the causal role of $\mathrm{C} 3 \mathrm{a}$ in hypertension.

\section{Strain dependence of liposomal hypertension in mice}

One self-evident question regarding the hypertensive effects of AmBisome and Abelcet in mice is whether it is limited to the NMRI mice, or it is universal among different mouse strains? To address this question we used Abelcet as a trigger of hypertension and $\mathrm{C} 57 \mathrm{Bl} / 6 \mathrm{~N}$ mice as a comparator strain. As shown in Figure $6 \mathrm{C}$ and D, there was only a minor quantitative difference in MBP responses in the two strains; Abelcet caused a somewhat stronger and longer hypertension in $\mathrm{C} 57 \mathrm{Bl} / 6 \mathrm{~N}$ than in NMRI mice, but the changes of HR were not different. These data, therefore, suggest that liposome-induced transient hypertension is not limited to NMRI mice, although the effects in different strains might be quantitatively different.

\section{Discussion}

\section{Features of CARPA in mice}

The identical time course of systemic hypertension, thrombocytopenia, leukocytosis, rise of TXB2, capillary leakage, ${ }^{27}$ $\mathrm{C}$ consumption and buildup of $\mathrm{C} 3 \mathrm{a}$ in the blood after injection of $\mathrm{C}$ activator zymosan and CVF leave little doubt about the association, most likely causal involvement of $\mathrm{C}$ activation in these transient physiological changes. Since they all are typical manifestations of human, ${ }^{1,2}$ rat, ${ }^{20,23}$ 


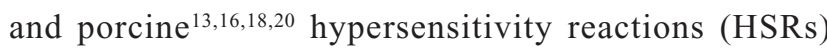
which were shown to be related to $\mathrm{C}$ activation, this study provides evidence for the first time that full-spectrum CARPA syndrome can arise in mice, just as in the abovementioned species. However, our study also shows that there are significant differences in these species regarding the features of CARPA. Notably, the reactive dose of zymosan and liposomes in the present mouse and in previous rat studies was roughly two orders of magnitude higher than those in pigs and hypersensitive humans, implying relatively low sensitivity of mice and rats for CARPA. Furthermore, in mice, the initial hemodynamic change is hypertension, which is followed (or not followed) by hypotension, while in pigs and rats the primary response is often hypotension..$^{3,20,28}$ In pigs, the initial hypotension may split the pulmonary hypertension to become biphasic. ${ }^{20,28}$

\section{Mechanism of hemodynamic changes: the puzzle of liposome reactions}

As for the mechanism of initial hypertension with or without subsequent hypotension and shock, the association of hypertension with significant $\mathrm{C}$ consumption and elevation of $\mathrm{C} 3 \mathrm{a}$ in blood indicates direct involvement of $\mathrm{C}$ activation in these changes, at least in the case of zymosan and CVF (Figure 7). As mentioned, this observation provides evidence for the presence of CARPA in mice. The exact mechanism of

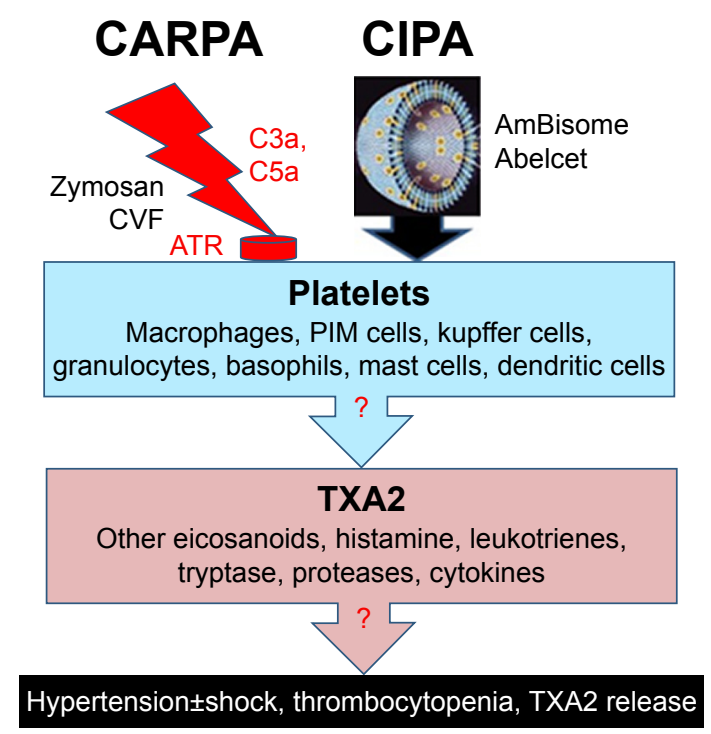

Figure 7 Double hit hypothesis of $C$ activator- and liposome-induced circulatory changes in mice.

Notes: Cells (blue) that can secrete vasoactive mediators (orange) can be stimulated either via anaphylatoxin-receptor (ATR, “AT hit"), or directly ((“C-independent hit") leading to CARPA and C-independent pseudoallergy (CIPA)). Zymosan and CVF act via ATR, while AmBisome and Abelcet via a direct hit. The entailing physiological changes are listed on a black background. Italicized entries are hypothetical.

Abbreviations: AT, anaphylatoxin; ATR, anaphylatoxin receptor; CARPA, C activationrelated pseudoallergy; CIPA, C-independent pseudoallergy; CVF, cobra venom factor. the causal role of $\mathrm{C}$ activation in the hypertensive response with or without subsequent hypotension is not clear. Anaphylatoxins and secondary mediators can all contribute to both effects, one example being the C5aR mediated hypotension in rodents. ${ }^{3}$ However, in the absence of $\mathrm{C} 5 \mathrm{a}$ measurement we cannot confirm or contradict a role of $\mathrm{C} 5 \mathrm{a}$ in these changes, and the relative contributions of different activation mechanisms ${ }^{28-30}$ (Figure 7) need to be explored in further studies.

In contrast to the $\mathrm{C}$ activators, the hypertension caused by AmBisome and Abelcet, a frequent side effect of liposomal Amphotericin B, ${ }^{31}$ was not associated with $\mathrm{C} 3 \mathrm{a}$ elevation or $\mathrm{C}$ consumption. This argues against $\mathrm{C}$ proteins playing a direct role in this change. Nevertheless, the finding that the $\mathrm{C} 3 \mathrm{aR}$ antagonist SB-290157 attenuated the hypertensive effect of Abelcet indicates at least a partial role of $\mathrm{C} 3 \mathrm{a}$ or other $\mathrm{C} 3 \mathrm{aR}$ agonists. Furthermore, we have no information on $\mathrm{C} 5 \mathrm{a}$, which can form independent of $\mathrm{C} 3$ conversion via the extrinsic complement pathway, ${ }^{32}$ thus a role of $\mathrm{C} 5$ a cannot be excluded even in lack of evidence of significant $\mathrm{C}$ activation.

There are several limitations of this study. One is that we used only male mice although pathophysiological processes can be different in the two sexes (see NIH notice NOT-OD-15-102). So, we cannot exclude that female mice respond differently. Also, the presence of CARPA was shown only for zymosan and CVF, which are strong $\mathrm{C}$ activators with many more biological effects. Thus, in addition to $\mathrm{C}$ activation, other $\mathrm{C}$-independent processes could also contribute to the observed changes, referred to as $\mathrm{C}$-independent pseudoallergy (CIPA, Figure 7). Furthermore, there is a large number of unaddressed questions in the study, such as the mechanism of liposome-induced CIPA, the tachycardic effect of $\mathrm{C} 3 \mathrm{aR}$ inhibitor and the role of Amphotericin-B in the effects of AmBisome and Abelcet.

\section{Conclusion}

The systematic analysis of CARPA symptoms in mice represents, to our best knowledge, the first effort to explore the use of mice as a model of human HSRs. We confirm the presence of this phenomenon in this species but only for strong $\mathrm{C}$ activators, not for the studied liposomes. These findings represent a translational value, since understanding the details of a complex, multi-channel cross-talk between the immune and circulatory systems in different species will help to predict and prevent HSRs in man. Although the exact mechanisms of physiological changes reported in this study have not been clarified, the results fit in the double hit hypothesis claiming C-dependent (CARPA) and independent 
(CIPA) stimulation of allergy mediating cells as underlying mechanism. ${ }^{2,17}$ (Figure 7).

\section{Acknowledgments}

This work was supported by the European Union ("NanoAthero" project FP7-NMP-2012 LARGE-6-309820) the Hungarian Scientific Research Fund (OTKA/NFKI) project K-113164, Budapest, Hungary, and the Applied Materials and Nanotechnology Center of Excellence, Miskolc University, Miskolc, Hungary. The study was supported in part (B.W.N and M.A.D) by federal funds from the National Cancer Institute, National Institutes of Health, under contract HHSN261200800001E. The content of this publication does not necessarily reflect the views or policies of the Department of Health and Human Services, nor does mention of trade names, commercial products, or organizations imply endorsement by the US Government. Sincere thanks are due to Marieluise Wippermann (TECOMedical, $A G$ ) for support of this study.

\section{Disclosure}

The authors report no conflicts of interest in this work.

\section{References}

1. Szebeni J. Complement activation-related pseudoallergy: a new class of drug-induced acute immune toxicity. Toxicology. 2005;216(2-3): $106-121$.

2. Szebeni J. Complement activation-related pseudoallergy: a stress reaction in blood triggered by nanomedicines and biologicals. Mol Immunol. 2014;61(2):163-173.

3. Dézsi L, Rosivall L, Hamar P, Szebeni J, Szénási G. Rodent models of complement activation-related pseudoallergy: inducers, symptoms, inhibitors and reaction mechanisms. Eur J Nanomed. 2015;7(1):15.

4. Proctor LM, Moore TA, Monk PN, Sanderson SD, Taylor SM, Woodruff TM. Complement factors C3a and C5a have distinct hemodynamic effects in the rat. Int Immunopharmacol. 2009;9(6):800-806.

5. Engström G, Hedblad B, Berglund G, Janzon L, Lindgärde F. Plasma levels of complement $\mathrm{C} 3$ is associated with development of hypertension: a longitudinal cohort study. J Hum Hypertens. 2007;21(4):276-282.

6. Ng TT, Denning DW. Liposomal amphotericin B (AmBisome) therapy in invasive fungal infections. Evaluation of United Kingdom compassionate use data. Arch Intern Med. 1995;155(10):1093-1098.

7. Schneider P, Klein RM, Dietze L, Söhngen D, Leschke M, Heyll A. Anaphylactic reaction to liposomal amphotericin (AmBisome). $\mathrm{Br} J$ Haematol. 1998;102(4):1108-1109.

8. Borro JM, Solé A, de La Torre M, et al. Efficiency and safety of inhaled amphotericin B lipid complex (Abelcet) in the prophylaxis of invasive fungal infections following lung transplantation. Transplant Proc. 2008;40(9):3090-3093.

9. Cook G, Franklin IM. Adverse drug reactions associated with the administration of amphotericin B lipid complex (Abelcet). Bone Marrow Transplant. 1999;23(12):1325-1326.

10. Furebring M, Öberg G, Sjölin J. Side-effects of amphotericin B lipid complex (Abelcet) in the Scandinavian population. Bone Marrow Transplant. 2000;25(3):341-342.

11. Chanan-Khan A, Szebeni J, Savay S, et al. Complement activation following first exposure to pegylated liposomal doxorubicin (Doxil): possible role in hypersensitivity reactions. Ann Oncol. 2003;14(9):1430-1437.
12. Kozma Gergely T, Mészáros T, Weiszhár Z. Variable association of complement activation by rituximab and paclitaxel in cancer patients in vivo and in their screening serum in vitro with clinical manifestations of hypersensitivity: a pilot study. Eur J Nanomed. 2015;7:289.

13. Szebeni J, Fontana JL, Wassef NM, et al. Hemodynamic changes induced by liposomes and liposome-encapsulated hemoglobin in pigs: a model for pseudoallergic cardiopulmonary reactions to liposomes. Role of complement and inhibition by soluble CR1 and anti-C5a antibody. Circulation. 1999;99(17):2302-2309.

14. Szebeni J, Baranyi L, Savay S, et al. Liposome-induced pulmonary hypertension: properties and mechanism of a complement-mediated pseudoallergic reaction. Am J Physiol Heart Circ Physiol. 2000;279(3): H1319-H1328.

15. Szebeni J, Baranyi L, Sávay S, et al. Complement activation-related cardiac anaphylaxis in pigs: role of C5a anaphylatoxin and adenosine in liposome-induced abnormalities in ECG and heart function. Am J Physiol Heart Circ Physiol. 2006;290(3):H1050-H1058.

16. Szebeni J, Bedőcs P, Csukás D, Rosivall L, Bünger R, Urbanics R. A porcine model of complement-mediated infusion reactions to drug carrier nanosystems and other medicines. Adv Drug Deliv Rev. 2012; 64(15):1706-1716.

17. Szebeni J, Bedőcs P, Urbanics R, et al. Prevention of infusion reactions to pegylated liposomal doxorubicin via tachyphylaxis induction by placebo vesicles: a porcine model. J Control Release. 2012;160(2): 382-387.

18. Urbanics R, Bedőcs P, Szebeni J. Lessons learned from the porcine CARPA model: constant and variable responses to different nanomedicines and administration protocols. Eur J Nanomed. 2015;7(3):219.

19. Jackman JA, Mészáros T, Fülöp T, Urbanics R, Szebeni J, Cho NJ. Comparison of complement activation-related pseudoallergy in miniature and domestic pigs: Foundation of a validatable immune toxicity model. Nanomedicine. 2016;12(4):933-943.

20. Dézsi L, Fülöp T, Mészáros T, et al. Features of complement activationrelated pseudoallergy to liposomes with different surface charge and pegylation: comparison of the porcine and rat responses. $J$ Control Release. 2014;195:2-10.

21. Adler-Moore JP, Proffitt RT. Development, characterization, efficacy and mode of action of ambisome, a unilamellar liposomal formulation of amphotericin B. J Liposome Res. 1993;3(3):429-450.

22. Janoff AS, Boni LT, Popescu MC, et al. Unusual lipid structures selectively reduce the toxicity of amphotericin B. Proc Natl Acad Sci USA. 1988;85(16):6122-6126.

23. Baranyi L, Szebeni J, Sávay S. Complement-dependent shock and tissue damage induced by intravenous injection of cholesterol-enriched liposomes in rats. J Appl Res. 2003;3(3):221-231.

24. Cedrone E, Neun B, Rodriguez J, et al. Anticoagulants influence the performance of in vitro assays intended for characterization of nanotechnology-based formulations. Molecules. 2017;23(1):12.

25. Mollnes TE, Brekke OL, Fung M, et al. Essential role of the C5a receptor in E coli-induced oxidative burst and phagocytosis revealed by a novel lepirudin-based human whole blood model of inflammation. Blood. 2002;100(5):1869-1877.

26. Catella F, Healy D, Lawson JA, Fitzgerald GA. 11-Dehydrothromboxane B2: a quantitative index of thromboxane A2 formation in the human circulation. Proc Natl Acad Sci U S A. 1986;83(16):5861-5865.

27. Marceau F, Lundberg C, Hugli TE. Effects of the anaphylatoxins on circulation. Immunopharmacology. 1987;14(2):67-84.

28. Mészáros T, Kozma GT, Shimizu T, et al. Involvement of complement activation in the pulmonary vasoactivity of polystyrene nanoparticles in pigs: unique surface properties underlying alternative pathway activation and instant opsonization. Int J Nanomedicine. 2018;13:6345-6357.

29. Szebeni J, Bedőcs P, Rozsnyay Z, et al. Liposome-induced complement activation and related cardiopulmonary distress in pigs: factors promoting reactogenicity of Doxil and AmBisome. Nanomedicine. 2012;8(2): 176-184.

30. Szebeni J, Simberg D, González-Fernández Á, Barenholz Y, Dobrovolskaia MA. Roadmap and strategy for overcoming infusion reactions to nanomedicines. Nat Nanotechnol. 2018;13(12):1100-1108. 
31. Ringdén O, Jønsson V, Hansen M, Tollemar J, Jacobsen N. Severe and common side-effects of amphotericin B lipid complex (Abelcet). Bone Marrow Transplant. 1998;22(7):733-734.
32. Noris M, Remuzzi G. Overview of complement activation and regulation. Semin Nephrol 2013;33:479-492.

\section{Publish your work in this journal}

The International Journal of Nanomedicine is an international, peerreviewed journal focusing on the application of nanotechnology in diagnostics, therapeutics, and drug delivery systems throughou the biomedical field. This journal is indexed on PubMed Central, MedLine, CAS, SciSearch $\AA$, Current Contents ${ }^{\circledR} /$ Clinical Medicine,
Journal Citation Reports/Science Edition, EMBase, Scopus and the Elsevier Bibliographic databases. The manuscript management system is completely online and includes a very quick and fair peer-review system, which is all easy to use. Visit http://www.dovepress.com/ testimonials.php to read real quotes from published authors.

Submit your manuscript here: http://www.dovepress.com/international-journal-of-nanomedicine-journal 